\title{
Effect of gonadotrophins and testosterone on the seminiferous tubules of the immature rat
}

\author{
H. E. Chemes, M. A. Rivarola and C. Bergadá \\ División de Patología and Centro de Investigaciones Endocrinológicas (C.E.D.I.E.), \\ División de Endocrinologia, Hospital de Niños, Gallo 1330, Buenos Aires, Argentina
}

\begin{abstract}
Summary. The actions of HCG and PMSG for different periods and of testosterone on the immature rat testis were studied. Short-term administration of HCG (1-3 days) induced an early meiotic and postmeiotic stimulatory effect but a decrease in spermatogonial numbers. Administration of $\mathrm{HCG}$ for longer periods (10 days) caused a reduction in numbers of all cell types. Treatment with HCG + PMSG reduced the amount of inhibition, while PMSG alone resulted in histological and humoral signs of stimulation of the interstitial tissue and the meiotic and postmeiotic stages; the numbers of spermatogonia were not affected. Testosterone caused stimulation of the meiotic and postmeiotic stages and a reduced number of spermatogonia. It is concluded that while PMSG directly stimulates spermatogonia, HCG acts through testosterone secretion at the meiotic and postmeiotic stages. The early inhibitory effects of HCG and testosterone on spermatogonial numbers could be ascribed to the inhibition of endogenous FSH by androgens.
\end{abstract}

\section{Introduction}

It is possible that the hormonal requirements for the induction of spermatogenesis in immature mammals could be different from those needed for its maintenance in adult animals. There are, however, certain doubts about the mechanism of action of gonadotrophins and steroids in the induction of the spermatogenic cycle, as well as about the ratios between the two gonadotrophins needed to assure its normal development (Bergadá \& Mancini, 1973). While Courot (1970) has suggested that FSH could be the main gonadotrophin in the prepubertal period, Lostroh (1969) has stated that FSH and LH may act in a synergistic way. On the basis of cultures of seminiferous tubules and experimental evidence from immature rats, Steinberger \& Steinberger (1967) and Steinberger \& Duckett (1965), following Cutuly \& Cutuly (1940) and Tonutti (1954), have suggested that no hormones were required for spermatogenesis to proceed from the early spermatogonial steps up to those of late pachytene, and that FSH and testosterone would be necessary only for the final stages of the cycle. A requirement for androgens, LH, and other pituitary hormones (GH and TSH) has also been suggested (Simpson \& Evans, 1946; Woods \& Simpson, 1961; Mancini, 1968; Mills \& Means, 1972). Spermatogonial renewal and the early steps of meiosis have been considered to be under the control of FSH (Greep et al., 1936; Courot, 1970; Davies, 1971; Mills \& Means, 1972). The present study was carried out in order to determine the action of testosterone and gonadotrophins in immature rats with special reference to the mechanism and places of action of these hormones in the spermatogenic cycle.

\section{Materials and Methods}

\section{Histological procedures}

All animals were killed at 26 days of age. The testes were fixed in Cleland's solution and, after embedding in paraffin wax, $5 \mu \mathrm{m}$ sections were obtained and stained with haematoxylin and eosin or PAS-haematoxylin. At 26 days of age, there is a transition between the meiotic and postmeiotic 
stages and the appearance of the first spermatids takes place (Clermont \& Perey, 1957). The seminiferous tubules were grouped according to the cellular associations that have been shown in 15-18day-old rats (Clermont \& Perey, 1957). In 26-day-old rats, there were four typical associations. In Type 1 there were few type A spermatogonia; the tubules contained mainly spermatogonia of the intermediate type, spermatocytes at zygotene and early spermatids. In Type 2 there were again few type A spermatogonia; type B spermatogonia predominated, with spermatocytes at pachytene and early spermatids. In Type 3 there were few spermatogonia of type A and the tubules predominantly contained premeiotic resting spermatocytes, spermatocytes at pachytene and some early spermatids. In Type 4, type A spermatogonia were abundant and the spermatocytes were mainly at leptotene and diplotene, although some were at zygotene and secondary spermatocytes could be seen (see Plate 1). In each cross-section of a seminiferous tubule, the following parameters were recorded: tubular diameter, the types of spermatogonia (A, Intermediate (In) and B), premeiotic spermatocytes and the different stages of meiosis in spermatocytes (leptotene, zygotene, pachytene, and diplotene) and spermatids. The pachytene spermatocytes of tubules of types 2 and 3 were recorded separately.

\section{Experiment 1}

The 50 Sprague-Dawley male rats used to investigate the effects of HCG were those studied as part of another study (Chemes et al., 1976). The animals were allocated to five groups of ten. Rats in Group 1 were given daily injections of diluent (distilled water) only for 5 days. Group 2 rats were given a single dose of 30 i.u. HCG (Endocorión: Elea Laboratories) at 25 days of age. Group 3 rats received daily injections of 15 i.u. HCG from the 23rd to the 25th day of life. Rats in Group 4 were given five daily injections of 15 i.u. HCG beginning on Day 21 of age. Group 5 rats were injected daily with single doses of 10 i.u. from the 16th to the 25th day after birth. The HCG was administered intraperitoneally. For each animal 25 cross-sections of tubules were studied, i.e. 250 tubules in each experimental group. Equivalent amounts of each type of tubules were counted in each animal and the data were analysed with the Tuckey-Keuls test (Keuls, 1952).

\section{Experiment 2}

Group 6 contained five immature rats treated with an intraperitoneal injection of 10 i.u. HCG + a subcutaneous injection of 10 i.u. PMSG (Eleagol: Elea Laboratories) daily from Day 16 until Day 25. Autopsy was performed on Day 26. The cell types in a total of 140 tubules were recorded.

\section{Experiment 3}

Three untreated animals in Group 7 acted as controls. Five immature rats in Group 8 were given a subcutaneous injection in olive oil of $2.5 \mathrm{mg}$ testosterone propionate (Sterandryl 50: Roussel) $+4 \mathrm{mg}$ testosterone oenanthate (Testovirón Depot: Schering) 3 days before autopsy, and $3.5 \mathrm{mg}$ testosterone propionate $+6 \mathrm{mg}$ testosterone oenanthate 2 days before autopsy. Two different

\section{EXPLANATION OF PLATE 1}

Testicular tubules illustrating the four types of cellular associations recognized in 26-day-old rats. PAShaematoxylin, $\times 800$.

Fig. 1. Type 1 tubule: three intermediate (In) type spermatogonia, one type A (A) spermatogonium, spermatocytes at zygotene $(Z)$ and early spermatids $(T)$ at the Golgi and cap phase.

Fig. 2. Type 2 tubule: three type B (B) spermatogonia, one type A (A) spermatogonium, spermatocytes at pachytene $(P)$ and early spermatids $(T)$.

Fig. 3. Type 3 tubule: six resting (R) spermatocytes, spermatocytes at pachytene $(P)$ and four spermatids with more advanced development of the nuclear cap.

Fig. 4. Type 4 tubule: two type A (A) spermatogonia, and spermatocytes at leptotene (L) and diplotene (D). 
PLATI:

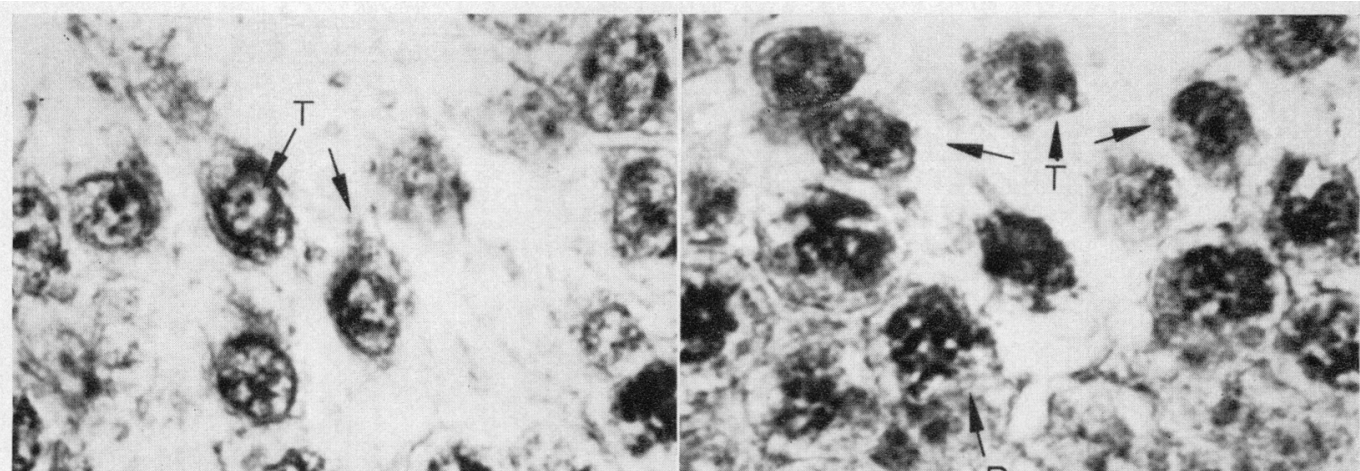

- 4 , 4 , not

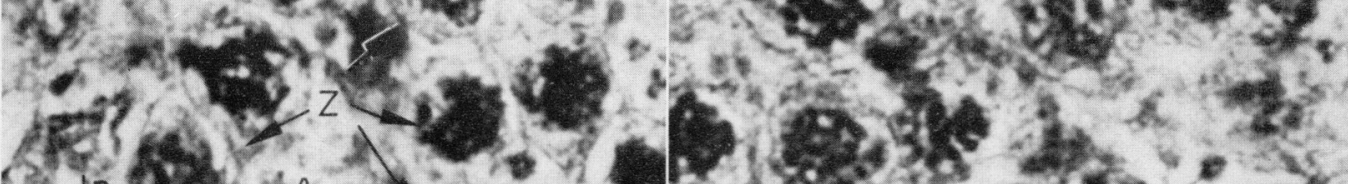

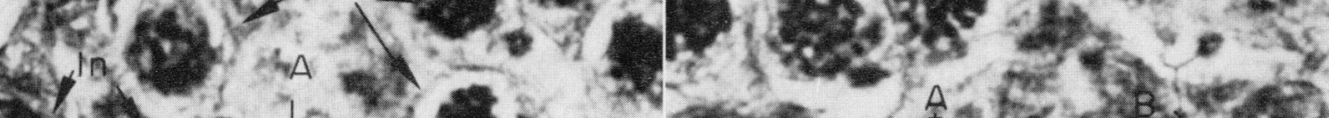

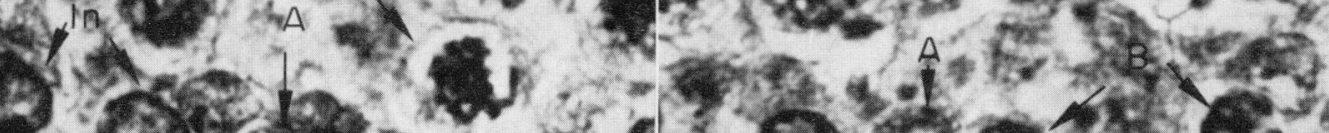

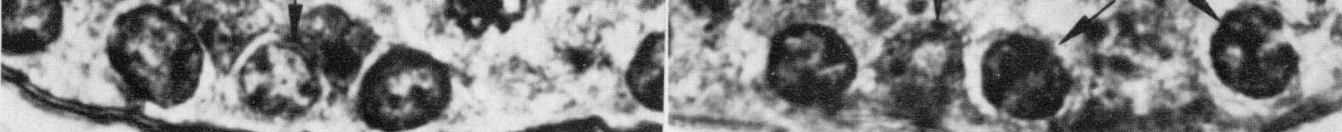

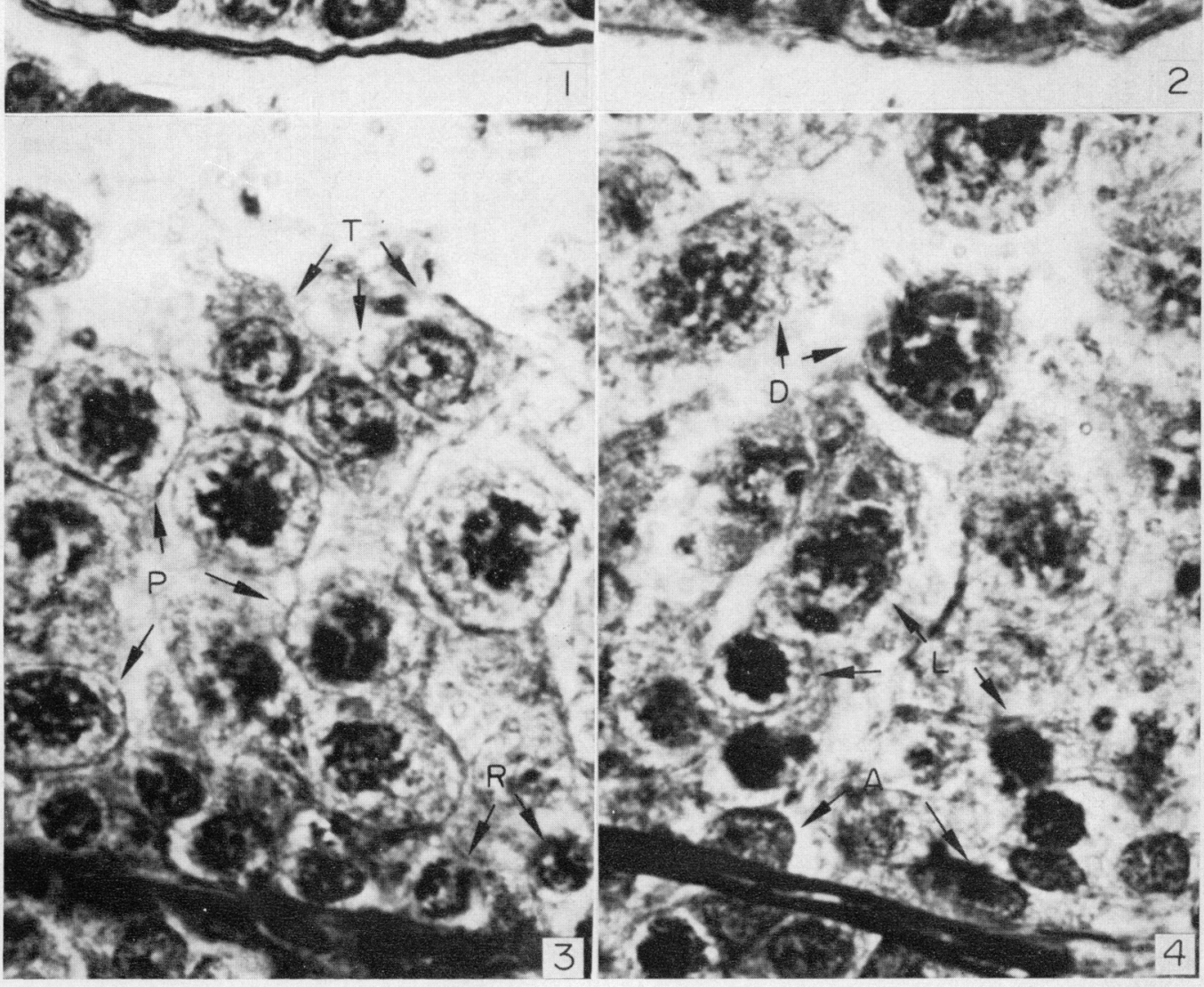


I'AM 2

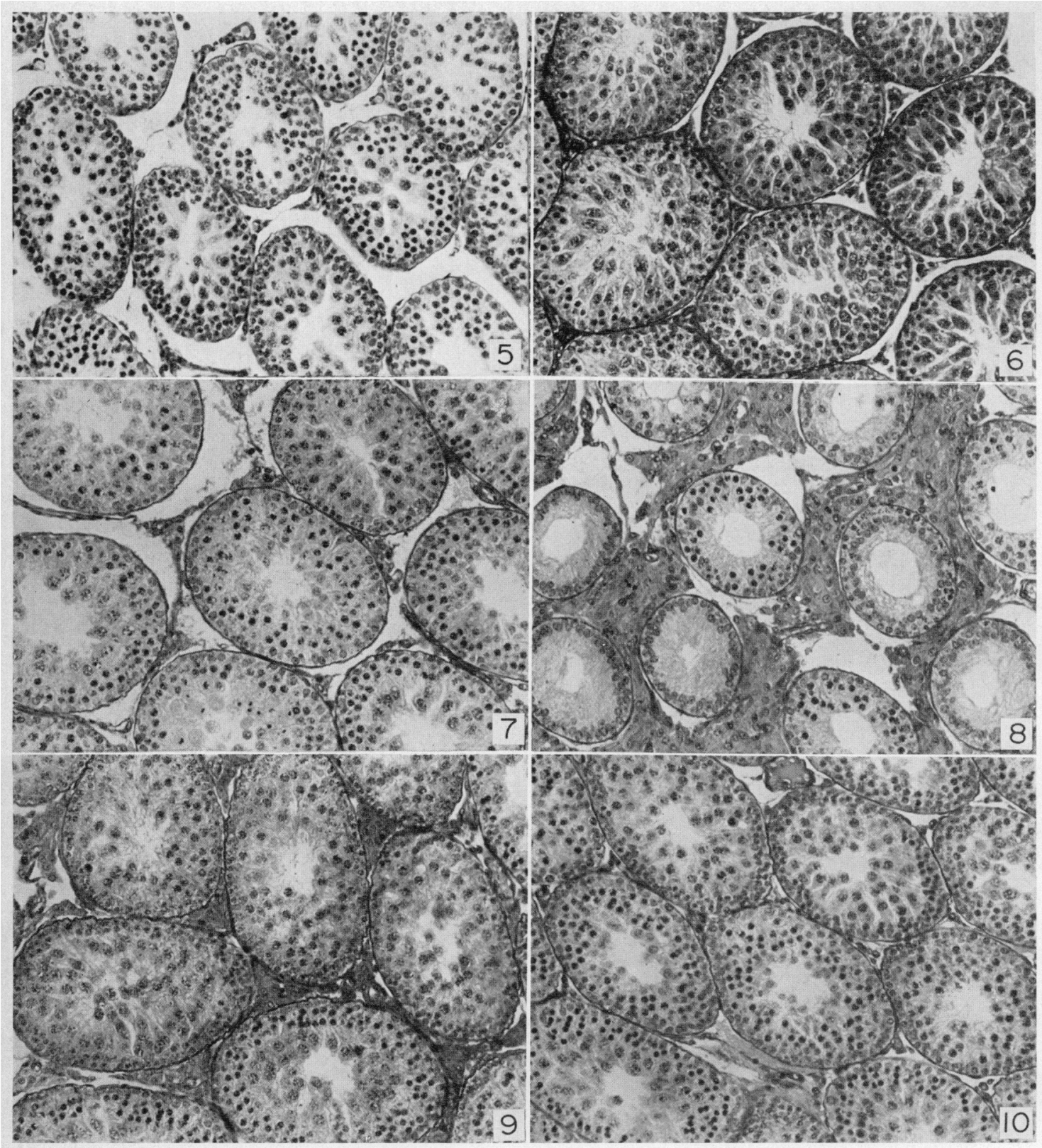


compounds of testosterone were used in an attempt to obtain stable plasma levels. Group 9 rats received daily subcutaneous injections of 15 i.u. PMSG from Day 21 until Day 25. All animals were killed at Day 26. Between 120 and 150 tubules were counted in each group and statistical analyses were performed with the least significant difference test (Steel \& Torrie, 1960).

\section{Results}

The assessments of the various cell types (Plate 2) in the different groups of rats are shown in Table 1. In Groups 2 and 3, pachytene and diplotene spermatocytes and spermatids, as well as tubular diameter showed a significant increase, but all values except the tubule diameter had fallen after 10 days of treatment with HCG (Group 5). Treatment with PMSG as well as HCG (Group 6) resulted in higher cellular counts compared to those for Group 5 rats, although only the numbers of A spermatogonia and pachytene and diplotene spermatocytes were similar to those of the control group. Tubule diameter was higher in Group 6 than in Groups 5 and 1. Treatment with testosterone stimulated meiotic and postmeiotic stages and tubule diameter, and depressed spermatogonial numbers, whereas PMSG affected only the meiotic and postmeiotic stages and tubule diameter. In the animals treated with testosterone, the interstitial tissue was atrophic, but in the PMSG treated rats it was hyperplastic (Plate 2, Figs 9 and 10). Stimulatory effects upon accessory sex glands were noted with increased weights (weight of seminal vesicles and prostate in Group 7 was $50 \mathrm{mg}$, in Group $8,75 \mathrm{mg}$ and in Group 9, $70 \mathrm{mg}$ ). The ratios between the counts of the different cell types were corrected by the formula of Abercrombie (1946), $T=C_{0} S / S+D$ in which $T=$ true count, $C=$ crude count, $S=$ thickness of section, $D=$ nuclear diameter, to eliminate errors due to variation in nuclear diameters and are shown in Table 2. There were no differences in the spermatogonial stages but the ratios of A:Intermediate and A:B spermatogonia were slightly lower than those found by Clermont \& Perey (1957) in animals of the same age. The cellular yield from meiosis improved in Groups 2, 3, 8 and 9 to give a twofold increase in the number of pachytene and diplotene spermatocytes formed from each premeiotic resting spermatocyte which enters meiosis.

\section{Discussion}

Greep et al. (1936), Simpson \& Evans (1946), Woods \& Simpson (1961) and Bergadá \& Mancini (1973) have mentioned that LH has gametogenic effects that could be mediated by testicular testosterone, although Maddock \& Nelson (1952) reported interstitial stimulation and tubular damage in men treated for long periods of time with HCG, and suggested that FSH inhibition by high testosterone and oestradiol levels might be responsible. Working with young and adult rats, Shay et al. (1941) and Ludwig (1950) showed inhibitory effects on spermatogenesis with low doses of testosterone and stimulatory effects with higher doses, suggesting that the former induced gonadotrophic inhibition, and the latter acted directly on the seminiferous epithelium.

Our findings of depressive effects of long-term administration of HCG are in accordance with those of Maddock \& Nelson (1952) in humans, but we have also noted an early gametogenic action

\section{EXPLANATION OF PLATE 2}

Representative sections of the testes of 26-day-old rats subjected to various experimental treatments. $\mathrm{H} \& \mathrm{E}, \times 128$.

Fig. 5. Group 1: no treatment.

Fig. 6. Group 2: 30 i.u. HCG for 1 day.

Fig. 7. Group $3: 15$ i.u. HCG/day for 3 days.

Fig. 8. Group 5: 10 i.u. HCG/day for 10 days.

Fig. 9. Group 8: testosterone treatment (see text).

Fig. 10. Group 9: 15 i.u. PMSG/day for 5 days. 


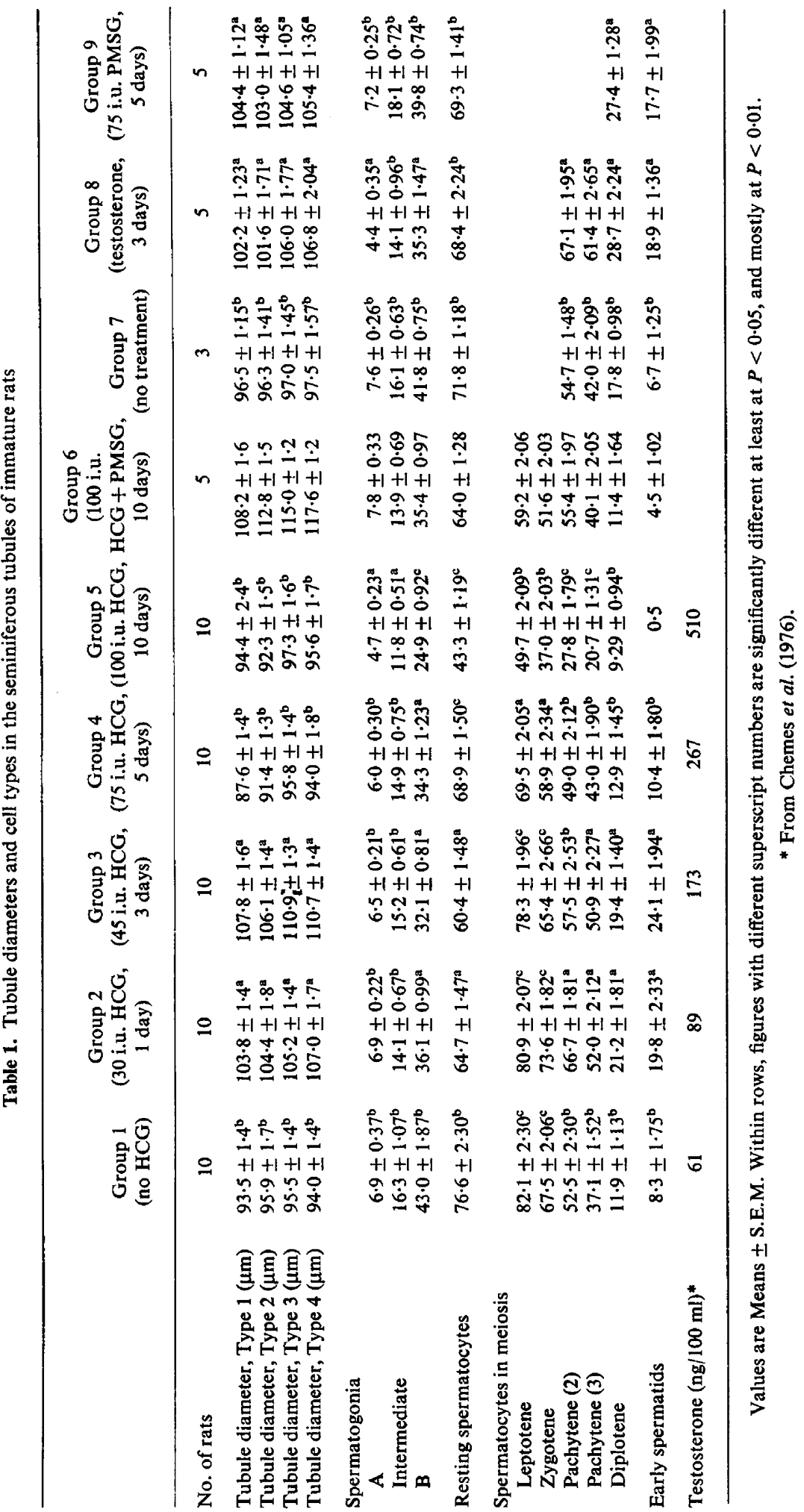


Table 2. The ratios between the different cellular types in the seminiferous tubules of immature rats subjected to various treatments

\begin{tabular}{lcccc}
\hline & A: In & A:B & B: R & R:D \\
\hline Group 1 (control) & $1: 3 \cdot 7$ & $1: 9 \cdot 8$ & $1: 2 \cdot 1$ & $9 \cdot 1: 1$ \\
Group 2 (HCG, 1 day) & $1: 3 \cdot 8$ & $1: 9 \cdot 6$ & $1: 2 \cdot 1$ & $4 \cdot 3: 1$ \\
Group 3 (HCG, 3 days) & $1: 3 \cdot 8$ & $1: 8 \cdot 1$ & $1: 2 \cdot 2$ & $4 \cdot 4: 1$ \\
Group 4 (HCG, 5 days) & $1: 4 \cdot 3$ & $1: 9 \cdot 8$ & $1: 2 \cdot 0$ & $4 \cdot 9: 1$ \\
Group 5 (HCG, 10 days) & $1: 4 \cdot 5$ & $1: 9 \cdot 4$ & $1: 2 \cdot 0$ & $6 \cdot 7: 1$ \\
Group 6 (HCG + PMSG, 10 days) & $1: 3 \cdot 3$ & $1: 8 \cdot 5$ & $1: 2 \cdot 1$ & $8 \cdot 0: 1$ \\
Group 8 (testosterone, 3 days) & $1: 5 \cdot 8$ & $1: 14 \cdot 6$ & $1: 2 \cdot 2$ & $3 \cdot 5: 1$ \\
Group 9 (PMSG, 5 days) & $1: 5 \cdot 1$ & $1: 11 \cdot 3$ & $1: 2 \cdot 0$ & $3 \cdot 6: 1$ \\
\hline
\end{tabular}

\footnotetext{
Crude counts were corrected by Abercrombie's formula before obtaining the cellular ratios. A, In, and B: A, Intermediate and B spermatogonia; $R$ : resting primary spermatocytes; D: spermatocytes at diplotene.
}

with stimulation of the late meiotic and early postmeiotic stages, to give a better yield of late meiotic spermatocytes and young spermatids from each premeiotic resting spermatocyte which enters meiosis. Therefore a protecting effect upon cellular loss during meiosis is evident. It is well known that a pattern of immaturity of spermatogenesis in developing rats is the high rate of meiotic cellular loss. The reported effects which show a yield more similar to adult rats would indicate a maturing action of HCG. Since the cellular ratios of the spermatogonial stages do not appear to be altered, the later inhibitory effects of $\mathrm{HCG}$ on cell numbers could be due to diminished renewal of stem type A spermatogonia.

On the other hand, PMSG showed a stimulatory effect on renewal of type A spermatogonia, blocking the inhibitory effects of HCG. Although there were signs of interstitial tissue hyperfunction, no diminution of A spermatogonia was observed, indicating a protective effect of PMSG probably related to its high FSH content. The effects of testosterone were identical to those caused by shortterm administration of HCG, supporting the interpretation that HCG acts through the stimulation of testosterone secretion by the testis. Lostroh (1969) found that FSH + LH markedly increased androgen production by the testis, and the histological and humoral indications of enhanced androgen secretion that we have observed in the animals treated with PMSG indicate that the meiotic and postmeiotic stimulatory effects found in the PMSG-treated animals were induced by testosterone. Besides this indirect action, PMSG has a direct effect upon spermatogonial proliferation. The inhibitory effects of long-term HCG administration would be produced by a depression of endogenous FSH by high testosterone and oestrogen levels. Reversal of these effects by addition of PMSG, which has a high FSH activity, would support this interpretation.

Steinberger \& Duckett (1965) and Steinberger (1971) have suggested that no hormones are required for spermatogenesis up to the late meiotic stages, but our findings on spermatogonial stimulation with PMSG indicate that FSH is needed at this point, and are in accordance with data presented by Mills \& Means (1972) and Davies (1971), as well as with the statement of Courot (1970) that FSH would be the predominant gonadotrophic hormone in immature animals. If it is accepted that the effects of $\mathrm{HCG}$ are mediated by testosterone, the combination of FSH and testosterone would command the hormonal control of spermatogenesis at those steps. The late meiotic actions of testosterone observed by us coincide with data reported by Steinberger (1971), and, as proposed by Shay et al. (1941), spermatogenic stimulation by testosterone is characterized by a quantitative cellular increase of elements already present and not by the appearance of more mature steps. Furthermore, it confirms the opinion of Woods \& Simpson (1961) that it is impossible to induce precocious spermatogenic maturation in immature rats.

The authors wish to express their acknowledgment to Dr Luis M. Becú for his advice and support. Thanks are due to Mr Sergio Penchansky for assistance with the photographs. One of us (H.E.C.) is a Fellow from the Municipalidad de Buenos Aires, and M.A.R. and C.B. are members of the 
Consejo Nacional de Investigaciones Científicas y Técnicas. The work was supported in part by grants from the Municipalidad de Buenos Aires, Fundación para la Investigación Pediátrica Máximo Castro, and Fundación de Endocrinología Infantil.

\section{References}

ABercrombie, M. (1946) Estimation of nuclear population from microtome sections. Anat. Rec. 94, 239-247.

BERgadÁ, C. \& MaNCINI, R.E. (1973) Effect of gonadotropins in the induction of spermatogenesis in human prepubertal boys. J. clin. Endocr. Metab. 37,935943.

Chemes, H.E., Rivarola, M.A. \& Bergadá, C. (1976) Effect of HCG on the interstitial cells and androgen production in the immature rat testis. $J$. Reprod. Fert. 46, 279-282.

Clermont, Y. \& Perey, B. (1957) Quantitative study of the cell population of the seminiferous tubules in immature rats. Am. J. Anat. 100, 241-260.

Courot, M. (1970) Effect of gonadotropins on the seminiferous epithelium of the immature testis. In The Human Testis, pp. 355-367. Eds E. Rosenberg \& A. C. Paulsen. Plenum Press, New York.

Cutuly, E. \& Cutuly, E.C. (1940) Observations on spermatogenesis in rats. Endocrinology 26, 503507.

Davies, A.G. (1971) Histological changes in the seminiferous tubules of immature mice following administration of gonadotrophins. J. Reprod. Fert. 25, 21-28.

Greep, R.O., Fevold, H.L. \& Hisaw, F.L. (1936) Effect of two hypophyseal gonadotropic hormones on the reproductive system of the male rat. Anat. Rec. 65, 261-271.

Keuls, M. (1952) The use of the studentized range in connection with an analysis of variance. Euphysica 1, 112-122.

LOSTROH, A.J. (1969) Regulation by FSH and ICSH (LH) of reproductive function in the immature male rat. Endocrinology 85, 438-445.

LUDWIG, D.J. (1950) The effect of androgens on spermatogenesis. Endocrinology 46, 453-481.

MADDOCK, W.O. \& Nelson, W.O. (1952) The effect of HCG in adult men: increased estrogen and 17 ketosteroid excretion, gynecomastia, Leydig cell stimulation and seminiferous tubule damage. J. clin. Endocr. Metab. 12, 985-1014.

Mancini, R.E. (1968) Bases histofisjológicas de la función testicular. In Testículo Humano, pp. 11-45, Ed. R. E. Mancini. Panamericana, Buenos Aires.

Mills, N.C. \& MEans, A.R. (1972) Sorbitol dehydrogenase of rat testis: changes of activity during development, after hypophysectomy and following gonadotropic hormone administration. Endocrinology 91, 147-156.

Shay, H., Gershon-Cohen, J., Paschkis, K.E. \& FeLs, S. (1941) Inhibition and stimulation of testes in rats treated with testosterone propionate. Endocrinology 28, 485-494.

Simpson, M.E. \& Evans, H.M. (1946) Comparison of the spermatogenic and androgenic properties of testosterone propionate with those of pituitary ICSH in hypophysectomized 40-day-old male rats. Endocrinology 39, 281-285.

Steel, R.J.D. \& ToRrie, J.H. (1960) Principles and Procedures of Statistics, pp. 106-107. McGraw-Hill, New York.

Steinberger, A. \& Steinberger, E. (1967) Factors affecting spermatogenesis in organ cultures of mammalian testes. J. Reprod. Fert., Suppl. 2, 117-124.

STEINBERGER, E. (1971) Hormonal control of mammalian spermatogenesis. Physiol. Rev. 51, 1-22.

Steinberger, E. \& DucketT, G.E. (1965) The effect of estrogen or testosterone on initiation and maintenance of spermatogenesis in the rat. Endocrinology 76, 1184-1189.

Tonutri, E. (1954) Action de la gonadotrophine chorionique sur les elements testiculaires au point de vue qualitatif et quantitatif. Sem. Hôp. Paris $\mathbf{3 0}$, 2135-2142.

Woods, M.C. \& Simpson, M.E. (1961) Pituitary control of the testis of the hypophysectomized rat. Endocrinology 69, 91-125. 